\title{
Comparative characterization of starch biopolymers extracted from cereals using two different techniques
}

\section{Caracterización comparativa de biopolímeros de almidón extraídos de cereales mediante dos técnicas diferentes}

\author{
RIVERA-ARREDONDO, Marisa* $\dagger^{1}$, RODRÍGUEZ-ÁNGELES, Mario Alberto ${ }^{2}$, MORALES-FÉLIX, \\ Verónica de Jesús ${ }^{1}$ and GAYTÁN-RUELAS, Marina ${ }^{1}$ \\ ${ }^{1}$ Universidad Tecnológica del Suroeste de Guanajuato, Carretera Valle-Huanimaro K. 1.2, Valle de Santiago, Guanajuato, \\ C.P.38400, México \\ ${ }^{1}$ Universidad Politécnica de Juventino Rosas, calle Hidalgo 102, Comunidad de Valencia, Juventino Rosas, Guanajuato, \\ 38253., Mexico
}

ID $1^{\text {st }}$ Author: Marisa, Rivera-Arredondo

ID $1^{\text {st }}$ Coauthor: Mario Alberto, Rodríguez-Ángeles

ID $2^{\text {nd }}$ Coauthor: Verónica de Jesús, Morales-Félix

ID $3^{\text {rd }}$ Coauthor: Marina, Gaytán-Ruelas

DOI: $10.35429 /$ JNAS.2020.20.7.21.26

Received March 21, 2020; Accepted June 30, 2020

\begin{abstract}
In the field of research and consequent elaboration of biopolymers it has been growing in the last decade, either due to the hardening of the environmental legislation of each country or due to ecological awareness, in any case the term biopolymer is quite broad, these being used as material premium in medicines, food supplements and of course in the production of bioplastics. Since the topic of interest is the comparative characterization of biopolymers using starch extracted from two different cereals, oats and rice, using the alkaline technique with $\mathrm{NaOH}$ treatment and the milling technique, assuming that the starch extracted from the Oryza sativa cereal presents chemical characteristics, geometric and mechanical superior in both techniques used unlike the polymers made with Avena sativa starch. These results suggest that the starch quality of each cereal is relevant for the production of biopolymers [1]. The commercially significant properties of starch, such as its mechanical strength and flexibility, depend on the strength and character of the crystalline region, which depends on the ratio of amylose and amylopectin.
\end{abstract}

\begin{abstract}
Resumen
En el campo de investigación y consiguiente elaboración de biopolímeros ha ido creciendo en la última década, ya sea debido a endurecimiento de las legislaciones ambientales de cada país o por conciencia ecológica, en todo caso el término biopolímero es bastante amplio, siendo estos utilizados como materia prima en medicamentos, suplementos alimenticios y por supuesto en la elaboración de bioplásticos. Puesto que el tema de interés es la caracterización comparativa de biopolímeros usando almidón extraído de dos cereales diferentes avena y arroz mediante la técnica alcalina con tratamiento de $\mathrm{NaOH}$ y la técnica de molienda, presumiendo que el almidón extraído del cereal de Oryza sativa presenta características químicas, geométricas y mecánicas superiores en ambas técnicas utilizadas a diferencia de los polímeros elaborados con almidón de Avena sativa. Estos resultados sugieren que la calidad de almidón de cada cereal es relevante para la elaboración de biopolímeros [1]. Las propiedades comercialmente significativas del almidón, tales como su resistencia mecánica y flexibilidad, dependen de la resistencia y de carácter de la región cristalina, la cual depende de la relación de amilosa y amilopectina.
\end{abstract}

Citation: RIVERA-ARREDONDO, Marisa, RODRÍGUEZ-ÁNGELES, Mario Alberto, MORALES-FÉLIX, Verónica de Jesús and GAYTÁN-RUELAS, Marina. Comparative characterization of starch biopolymers extracted from cereals using two different techniques. Journal of Natural and Agricultural Sciences. 2020, 7-20: 21-26

*Correspondence to Author (mriveraa@utsoe.edu.mx)

$\dagger$ Researcher contributing first author 


\section{Literary Review}

\section{Structural properties of natural starch.}

Starch grains are made up of macromolecules organized in layers. Two different polymer structures make up starches: amylose and amylopectin. About $20 \%$ of most starches is amylose and $80 \%$ amylopectin. Amylose molecules, located in the inner layers, are composed of approximately 200 to 20,000 glucose molecules linked by $\alpha-1,4$ glucosidic bonds (Figure 1) in unbranched or helix-wound chains. Many amylose molecules have some $\alpha-$ D- $(1,6)$ branches, approximately 0.3 to $0.5 \%$ of the total bonds. These are generally neither very long nor very short and are separated by great distances allowing the molecules to act, essentially with a linear polymer, forming strong films and fibers, and easily retrograded. As a consequence of the formation of helix-shaped chains, amylose fibers and films are more elastic than cellulose. Amylose is soluble in hot water which is due to the formation of a colloidal suspension. [2]

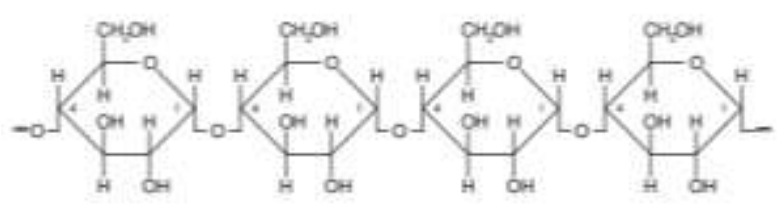

Figure 1 Segments of an amylose molecule [5]

The structure of amylopectin, located in the outer layers, is different from that of amylose. Amylopectin molecules contain $\alpha-1,4$ and $\alpha-1,6$ glycosidic linkages, as shown in Figure 2. Glycosidic linkages link glucose molecules in the amylopectin backbone. Branches of the main chain are frequently found, which are due to $\alpha-1,6$ glycosidic linkages with other glucose molecules. The connection points of the branches constitute between 4 and $5 \%$ of the total of the links. [6]

Amylopectin molecules are significantly larger than amylose molecules; some contain between 10,000 and 20 million glucose units [7]. The molecular weight of amylose is between 0.1 and one million $\mathrm{g} / \mathrm{mol}$. And that of amylopectin is between (10,000 to 1,000 million) $\mathrm{g} / \mathrm{mol}$ [5]. One of the most important properties of natural starch is its semi-crystallinity where amylopectin is the dominant component for crystallization in most starches.
The amorphous part is made up of branched regions of amylopectin and amylose. The commercially significant properties of starch, such as its mechanical strength and flexibility, depend on the strength and character of the crystalline region, which depends on the ratio of amylose and amylopectin and therefore on the type of plant, the distribution of the molecular weight, the degree of branching and the shaping process of each polymer component. [8]

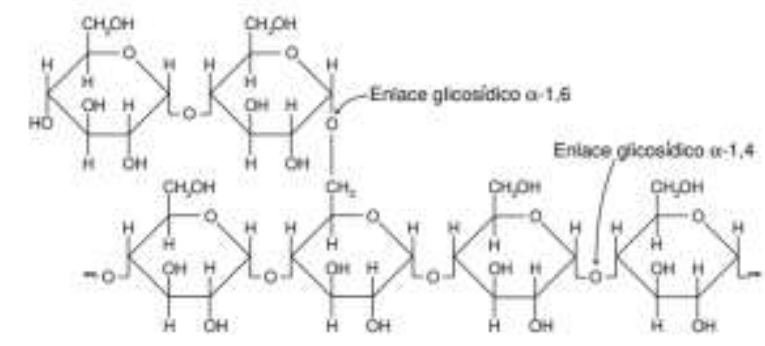

Figure 2 Segment of an amylopectin molecule [5]

\section{Gelatinization}

It is defined as the loss of crystallinity of starch grains in the presence of heat and high amounts of water with little or no depolymerization. Starch grains are insoluble in water and organic solvents. In aqueous suspension, the grains swell due to the action of heat, they tend to lose the properties that their semi-crystalline structure gives them and at a critical temperature they form a gel. [8]

During gelatinization, water initially penetrates the amorphous regions initiating swelling, which is seen by the decrease in birefringence. Then the water dislodges the starch chains from the surface of the crystals as the temperature increases; the thermal mobility of the molecules and the solvation produced by the swelling forces cause a decrease in crystallinity due to the unwinding of the double helices, until the granular structure is fragmented almost completely, obtaining a solid-gel.

The main difference between the preparation of thermoplastic starch (TPS) gels, foods, films, or processed materials is the amount of water or plasticizer during gelatinization or melting of the starch granules. 
To obtain thermoplastic starch, the starch is melted with the help of a relatively low amount of water during the extrusion, pressure molding or injection molding process, where the amount of water is below $20 \%$ in most of the cases. Some of the water is usually replaced by small amounts of glycerin. Differences in water and glycerin content and processing conditions such as: the speed of Obtaining a biodegradable polymer from corn starch, shear and temperature, produce differences in the formation of the starch network and in the morphology of the material produced. [9]

\section{Starch, as a raw material for the production of a bioplastic}

To convert a dry starch into a bioplastic material, it is necessary to break and melt its semicrystalline granular structure [10]. Starch without adequate additives (plasticizers) does not have the necessary properties to work as a thermoplastic. Plasticizers increase the flexibility of starch due to its ability to reduce the interaction of hydrogen bonds, in addition to increasing the molecular space [12]. Two types of ordering can be distinguished in thermoplastic starch after processing: residual crystallinity classified into type A, B and C forms caused by incomplete melting during plasticization and crystallinity induced during processing, according to the arrangements generated in the polymer chains according to [11] type $\mathrm{A}$ is common in cereal starches, $\mathrm{B}$ in tubers and $\mathrm{C}$ in certain roots and seeds.

The amount of residual crystallinity is related to the temperature and shear stress applied during processing; likewise the composition of the feed mixture also indirectly influences this amount of remaining crystallinity. Depending on some processing and storage conditions such as temperature and humidity, amorphous starch undergoes structural changes after cooling, based on: recrystallization of amylose and amylopectin in different crystal structures, phase separation and reorientation of the polymer. The molecular interactions (mainly hydrogen bonds between starch chains) that occur after cooling are called retrogradation [10]. This retrogradation also refers to the changes that take place in gelatinized starch from an initial amorphous state to a more ordered crystalline state. It occurs because starch gels are not thermodynamically stable.
According to the amylopectin chains, they are responsible for the retrogradation phenomena that are generated in the long term, while amylose is related to changes at shorter times. [10]

\section{Materials and Methods}

\section{Starch extraction}

The starch extraction method is carried out by the method used by Yamamoto, 1973 and some modifications. Where two different methodologies were used in each cereal [5]. In the first methodology, 100 grams of Oryza sativa and 100 grams of Avena sativa were subjected to a series of washes, firstly with $500 \mathrm{ml}$ of distilled water each, then $500 \mathrm{ml}$ of $0.1 \mathrm{~N} \mathrm{NaOH}$ were placed, continuing with water distilled, and finally a neutralization with $0.5 \mathrm{M} \mathrm{HCl}$, finally a washing with distilled water and centrifuged at $3000 \mathrm{rpm}$ for 20 minutes and drying at $60^{\circ} \mathrm{C}$ for 48 hours.

The process concluded with grinding and sieving. It should be mentioned that between each wash a 24-hour rest was maintained at $6^{\circ}$ C. The second methodology used the same quantities of $100 \mathrm{~g}$ of each cereal and consisted of letting both cereals rest with water for 24 hours. Subsequently, a simple grinding was carried out, it was centrifuged at $3000 \mathrm{rpm}$ for 20 minutes. Excess water was removed and the residue was dried in porcelain capsules in an oven whose parameters were $60^{\circ} \mathrm{C}$ for 48 hours. The process concluded with grinding and sieving. [13]

\section{Preparation of biopolymers}

For the elaboration of the biopolymers by means of an acid hydrolysis, it was carried out using the methodology of Rosales 2016 and adjustments. Where the same methodology was carried out, the variant was cereal starch. Table 1, later the mixture of each of the components was made and they were subjected to heating on a thermal plate at $80^{\circ} \mathrm{C}$ for 15 minutes, it was poured on waxed paper to later be spread by metal plates and allowed to dry for 48 hours at a temperature of $30^{\circ} \mathrm{C}$. This was done with each starch sample in triplicate. [14] 


\begin{tabular}{|c|c|c|c|c|c|}
\hline $\begin{array}{c}\text { Cereal and forms } \\
\text { extraction } \\
\text { of starch }\end{array}$ & $\begin{array}{l}\text { Quantity } \\
\text { (g) }\end{array}$ & $\begin{array}{c}\text { Water } \\
\text { distilled } \\
(\mathrm{ml})\end{array}$ & $\begin{array}{l}\text { Acid } \\
\text { citric } \\
\text { (g) }\end{array}$ & $\begin{array}{c}\text { Glycerin } \\
(\mathrm{ml})\end{array}$ & $\begin{array}{c}\text { Nomenclature } \\
\text { of the } \\
\text { treatment }\end{array}$ \\
\hline $\begin{array}{l}\text { Oryza sativa } \\
\mathrm{NaOH}\end{array}$ & 5 & 15 & 2.5 & 1.5 & $\mathrm{~T} 2 \mathrm{SO}$ \\
\hline $\begin{array}{l}\text { Oryza sativa } \\
\text { Molienda simple }\end{array}$ & 5 & 15 & 2.5 & 1.5 & T1MO \\
\hline $\begin{array}{l}\text { Avena sativa } \\
\mathrm{NaOH}\end{array}$ & 5 & 15 & 2.5 & 1.5 & T2SA \\
\hline $\begin{array}{l}\text { Avena sativa } \\
\text { Molienda simple }\end{array}$ & 5 & 15 & 2.5 & 1.5 & T1MA \\
\hline
\end{tabular}

Table 1 Manufacture of biopolymers

Own Source

\section{Chemical and mechanical analysis}

The moisture determination was carried out by the method described by NMX-F-083-1986. Likewise, the ash determination was carried out according to the guidelines described by NMXF-066-S-1978. The resistance determination was carried out in a texture analyzer, 0 to $1500 \mathrm{~g} /$ 0.20g, Brookfield, CT3-1500, where a biopolymer with dimensions of $15 \mathrm{~cm}$ long and 15 high was placed. The tensile strength was obtained by dividing the maximum force before the film broke by the transverse thickness of the film. The cutting force in $\mathrm{N}$.

\section{Geometric analysis}

The thickness determination $(\mathrm{mm})$ using a 0 $150 \mathrm{~mm}$ Vernier caliber consisted of placing a sample fragment in the tips for external measurements and subsequently the reading was taken on the digital marker.

\section{Results}

\section{Manufacture of biopolymers}

In Figure 3 shows the Oryza sativa biopolymers with the alkaline starch extraction technique (T2SO) and simple grinding (TIMO) and with promising characteristics in terms of their breaking strength and starch quality, where one of the most important properties of natural starches, which is their semicrystallinity where amylopectin is the dominant component for their crystallization, which is attributed to a favorable mechanical resistance due to the amylose and amylopectin ratio with a value of $(36.41 \pm 2.2$ and $62.75 \pm 2.2$ ). [15] According to their starch gelatinization temperature they vary from 70 to> $75^{\circ}$ C. [16]

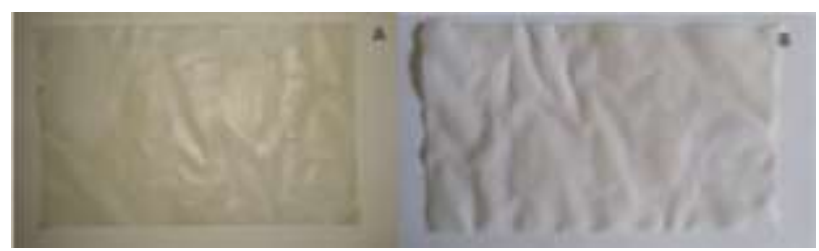

Figure 3 Oryza sativa biopolymers. A biopolymer by extraction of starch in alkaline solution (T2SO). B biopolymer by simple milling starch extraction (T1MO) Own Source

In Figure 4 shows the biopolymers of Avena satina with its two starch extraction techniques, it can clearly be seen that there is less resistance to its breaking force. The amylose content is relatively lower compared to that of other cereals [17] Oat starches had the lowest gelatinization temperatures, between 56.8 and $59.7^{\circ} \mathrm{C}$, using the same temperature for the production of biopolymers, they lost more moisture generating little resistance mechanics.

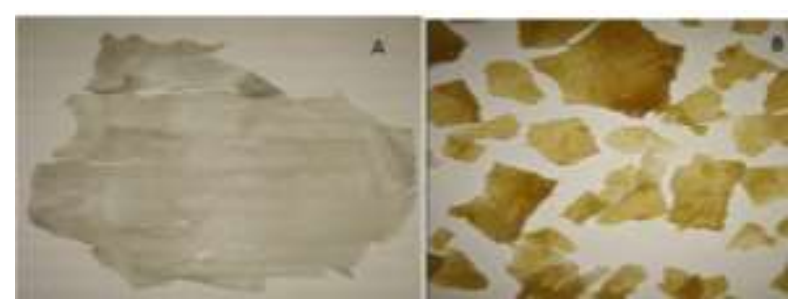

Figure 4 Biopolymer of Avena satina. A biopolymer extracted by alkaline solution (T2SA). B biopolymer extracted by simple milling (T1MA)

Own Source

\section{Chemical and mechanical analysis}

The relative humidity with the lowest percentage was presented by the T1MA polymer and following the T2SA both are the same starch different extraction technique. This indicates that Avena Sativa has a lower absorption by its semi-crystalline region with a lower ratio of amylose and amylopectin, generating a faster loss of water and generating less mechanical resistance. Table 2. Confirming with its percentage of minor ash in the starches of Avena sativa.

\begin{tabular}{|l|l|l|l|}
\hline T1MA & \multicolumn{1}{c|}{ T2SA } & \multicolumn{1}{c|}{ T1MO } & T2SO \\
\hline $5.08 \%$ & $7.55 \%$ & $9.30 \%$ & $9.32 \%$ \\
\hline \pm 0.15 & \pm 0.16 & \pm 0.05 & \pm 0.03 \\
\hline
\end{tabular}

Table 2 Moisture values in the treatments performed Own Source 


\begin{tabular}{|l|l|l|l|}
\hline T1MA & \multicolumn{1}{c}{ T2SA } & \multicolumn{1}{c|}{ T1MO } & T2SO \\
\hline $1.77 \%$ & $0.66 \%$ & $2.11 \%$ & $1.33 \%$ \\
\hline \pm 0.33 & \pm 0.2 & \pm 0.33 & \pm 0.3 \\
\hline
\end{tabular}

Table 3 Ash values in the treatments carried out. Own source

\section{Determination of the breaking force}

The shear force was obtained by dividing the maximum force before the film broke by the transverse thickness of the film. The cutting force in N. It was only determined with T1MO and T2SO by the appearance of their surfaces since the T1MA and T2SA treatments presented cracks in their entire surface. Confirming that it is attributed to the quality of cereal starch. Table 4.

\begin{tabular}{|l|l|l|l|}
\hline $\begin{array}{c}\text { T1MO } \\
\mathbf{N}\end{array}$ & \multicolumn{1}{c}{ T2SO } & \multicolumn{1}{c}{ T1MA } & T2SA \\
$\mathbf{N}$ & \multicolumn{1}{c|}{$\mathbf{N}$} & \multicolumn{1}{c|}{$\mathbf{N}$} \\
\hline 2.70 & 2.90 & 0 & 0 \\
\hline \pm 0.02 & \pm 0.05 & 0 & 0 \\
\hline
\end{tabular}

Table 4 Values of the determination of the breaking force Own Source

\section{Geometric analysis}

Finally, the thickness determination was made, showing the treatments as well as their standard deviations, there is no significant difference with respect to the thickness that can be attributed to the resistance or to its moisture and ash content. Table 5

\begin{tabular}{|c|c|c|c|}
\hline $\begin{array}{l}\text { T1MA } \\
\text { mm }\end{array}$ & $\begin{array}{l}\text { T2SA } \\
\mathrm{mm}\end{array}$ & $\begin{array}{l}\text { T1MO } \\
\text { mm }\end{array}$ & $\begin{array}{l}\text { T2SO } \\
\text { mm }\end{array}$ \\
\hline 0.61 & 0.65 & 0.61 & 0.68 \\
\hline \pm 0.14 & \pm 0.02 & \pm 0.06 & \pm 0.13 \\
\hline
\end{tabular}

Table 5 Grosor de los tratamientos realizados Own Source

\section{Conclusions}

The proportion of amylose and amylopectin play an important role in the properties of thermoplastic starches. The gelatinization temperature is the one at which the starch grains begin to absorb water and swell irreversibly in hot water, it is associated with the amylose content.
What can be distinguished is two types of ordering in thermoplastic starch after processing: residual crystallinity classified into type $\mathrm{A}, \mathrm{B}$ and $\mathrm{C}$ forms caused by incomplete melting during plasticization and induced crystallinity during processing, according to to the arrangements generated in the polymeric chains according to. [11] Type $\mathrm{A}$ is common in cereal starches, $\mathrm{B}$ in tubers, and $\mathrm{C}$ in certain roots. This indicates that even though the starch belongs to the same residual crystallinity classification.

The ratio of amylose and amylopectin is different in each type of cereal, according to the analyzes carried out it was obtained that the starch extracted by both extraction techniques from Oryza Sativa present better biopolymer properties, which attributes that the important thing is the starch and not there is a significant difference with respect to the starch extraction method.

\section{References}

[1] James E. Mark et al. High performance biodegradable materials from oriented starch derivates. U. S. patent 6,218,532 - Cincinnati, USA, 2001.

[2] Mario Demicheli. Biodegradable plastics from renewable sources http://www.jrc.es/pages/iptsreport/vol10/englis h/Env1E106.htm, 2000.

[3] Biocorp@. http://www.BiocorpUSA.com, 2002

[4] S. Mali et al. Microestructural characterization of Yam starch films, Carbohydrate Polymers, 50, 379-386 (2002).

[5] P. Matzinos et al. Processing and characterization of LDPE/starch products, Journal of Applied Polymer Science, 79, 25482557 (2000).

[6] R. L. Whistler y J. N. BeMiller. Carbohydrate chemistry for food scientists. St Paul: Eagan Press, 1997.

[7] Drew H. Wolfe. Qu'imica General Org'anica. McGraw-Hill segunda edici'on, 432433 (1996). 
[8] H. G. Fritz. Study of production of thermoplastics and fibers based mainly on biological material. European commission. Stuttgart German, 392 (1994). Universidad EAFIT 27| Obtenci'on y caracterizaci'on de un pol'1mero biodegradable a partir del almid'on de yuca

[9] J. Van Soest et al. Mechanical properties of thermoplastic waxy maize starch, Journal of Applied Polymer Science, 6, 1927-1937 (1996).

[10]Thiré, M.S.M.R., R.A. Simâo. y Andrade, T.C; Investigation of the surface morphology of plasticized cornstarch films, Acta Micro.: 12 (1), 175-179 (2003b)

[11] Van Soest, J.J.G. y otros tres autores; Changes in the mechanical properties of thermoplastic potato starch in relation with changes in B-type crystallinity, Carbohydr. Polym: 29 (3), 225-232 (1996b).

[12] Mali, S. y otros tres autores; Water sorption and mechanical properties of cassava starch films and their relation to plasticizing effect, Carbohydr. Polym: 60 (3), 283-289 (2005a).

[13] Yamamoto, K., Sawada, S., Onogaki, T. Properties of rice starch prepared byalkali method with various conditions. Denpun Kagaku (1973) 20, 99-104.

[14] Rosales. Obtención de biopolímeros plásticos a partir del almidón de malanga por el método de polimerización por condensación (2016)

[15] Landires, D.., Márquez G, Facultad de Ingeniería en Mecánica y Ciencias de la producción Escuela superior politécnica de litoral 09-01-5863 2013

[16] Manriquez, C., Cuevas F. Evaluacion de la calidad culinaria y molienda del arroz Cali, Colombia Pags 22-25

[17] Welch, R. W., \& McConnell, J. M. (2001). Avena. En D. A. V. Dendy \& B. J. Dobraszczyk (Eds.), Cereales y Productos Derivados: Química y Tecnología (pp. 457, 460, 461). Zaragoza, España: Editorial Acribia. 